\title{
Effect of Rhamnus prinoide (Gesho) Intercropping in Wheat Field on Soil Nutrient and Moisture in the Drylands of North Ethiopia
}

\author{
Destaalem Gebremeskel*, Buruh Abebe, Kidane Gidey and Tesfay Berihu \\ Department of Land Resources Management and Environmental Protection, College of Dryland \\ Agriculture and Natural Resources, Mekelle University, P.O. Box: 231, Mekelle, Ethiopia. \\ (*destaalem14@gmail.com)
}

\begin{abstract}
Rhamnus prinoide (Gesho) intercropping is a common practice with significant socioeconomic and ecological importance in Ganta-afoshum district. However, this practice is not well explored so far, especially from the perspective of its impact on sustainable land management while land degradation and low productivity is a challenge in the district. The objective of this study was to examine the effect of $R$. prinoide intercropping on soil nutrient and moisture. The study was conducted in Ganta-afoshum district, eastern zone of Tigray regional state where smallholder farmers practice $R$. prinoide intercropping. Soil samples were taken from farmland with dense, medium and sparse density of $R$. prinoide intercropping and from farmland without trees as a control for analysis. The density of the trees significantly affected the soil bulk density $(\mathrm{P}<0.05)$ Soil moisture content significantly increased with increasing soil depth and by the interaction effects of soil depth and density $(\mathrm{P}<0.05)$. Soil nitrogen concentration significantly influenced by the density and soil depth $(\mathrm{P}<0.05)$. Soil phosphorus and potassium concentration significantly affected by soil depth $(\mathrm{P}<0.05)$. Lower mean soil $\mathrm{pH}$ values were observed for soils under the farm with dense trees as compared to soils in open farm. Overall, the enhancing and exploitative effects of $R$. prinoide intercropping on soil nutrient and moisture is minimal. This could be the reason for being practiced and maintained by most farmers.
\end{abstract}

Keywords: Agro-forestry systems, $R$. prinoide intercropping, Spatial arrangement, Soil nutrient and moisture, Tigray, Ethiopia.

\section{INTRODUCTION}

Increasing human population has caused pronounced reduction in tree cover although trees remain an important element of most human-dominated landscapes throughout the tropics (Schroth and Sincliar, 2003). It is providing a wide range of important products and services, while underpinning the sustainability of the farming systems (Cooper et al., 1996). Maintaining soil fertility is the main aspect of sustainable land use. Low and declining soil fertility is recognized by many tropical farmers as the major constraint to agricultural production (Smaling et al., 1997). Trees can improve the nutrient balance of a site and nutrient cycling in a system (Schroth et al., 2003) and water-use efficiency in drylands (UNEP, 1992). When trees are present 
in crop fields they have a profound influence on majority components of water balance (Teixeira et al., 2003).

Strategic placing of trees in the landscape may prevent, enhance or direct flows of soil, water, nutrients, fire and organisms across the landscapes (Noordwijk et al., 1999). The tools that are available to the farmer for optimizing water balance, nutrient cycles and positive interaction are the selection of plant (and animal) species, their spatial and temporal arrangement (system design), and their management (Teixeira et al., 2003; Schroth et al., 2003). Intercropping is an efficient farming system for better resource utilization and improving productivity (Vandermeer, 1992). R. prinoide intercropping is a common practice in north Ethiopia. Rhamnus prinoides L'Herit, which belongs to the family of Rhamnaceae (Kokwaro, 1993), is a wide spread plant species in east, central and south African countries (Orwa et al., 2009). Its common name is dogwood and local name is "gesho". The African dogwood, $R$. prinoides (Rhamnaceae) is a dense shrub or a tree that grows up to $9 \mathrm{~m}$ high (Berhanu and Teshome, 1995), common in medium to high altitudes, and thrives in moist humus soils (Orwa et al., 2009).

$R$. prinoide trees are cultivated to control soil erosion, as a hedge or wind breaker, for shading and as an ornamental plant (Orwa et al., 2009). In Ethiopia, R. prinoides (gesho) is found growing in the wild and cultivated lands usually at altitudes of 1500-2500m (Berhanu and Teshome, 1995). In north Ethiopia, it is common especially in central and eastern parts of the Tigray regional state mainly in the Ahforom and Ganta-afeshum districts. $R$. prinoide intercropping is a dominant practice mainly for its commercial purposes and home consumption i.e. to make local drinks called Tella and Tej, similar to beer. It is also used by the local people as traditional medicine to treat different diseases such as tonsillitis (Birhanu, 2013), uvulitis (Andemariam, 2010), and hepatitis (d'Avigdor et al., 2014). Above all, the number of $R$. prinoides plants owned by the farmer is also used as an indicator of wealth and social status by the community.

Although, $R$. prinoide intercropping is a common practice in many areas in Tigray, north Ethiopia, it is not well explored and appreciated so far, especially from the perspective of sustainable land management. Hence, a study was conducted in Ganta-afoshum districts, eastern Tigray. Land degradation, nutrient deficiency and moisture stress are the production constraints in the area and land holding is small in the region ranging from 0.25 to 0.5 ha (BoARD, 2010). The emphasis given from scholars and research institutions on this issue is limited. As a result, 
the effort to assist farmers to improve productivity of $R$. prinoide intercropping based on scientific evidence is minimal. $R$. prinoide intercropping might have an impact on the status of soil nutrient of farmland through its above and below ground litter falls and its eco-physiological traits which requires examination for appropriate management. $R$. prinoide characterized as a species of humid or moist areas (Orwa et al., 2009) which is in contrary to the study area where moisture is the production constraint that requires examination on its impact on soil moisture in the farm land. Present paper examines the effect of $R$. prinoide intercropping in wheat field at varied density (dense, medium and sparse) on soil nutrient and soil moisture.

\subsection{Description of Study Area}

The study was conducted in the districts of Ganta-afoshum in the Eastern zone of the Tigray region, northern Ethiopia. The area is potential for $R$. prinoide production and has suitable agroecological and socioeconomic settings for the species to grow. The district has a geographical location of $14^{\circ} 07^{\prime}$ to $14^{\circ} 39^{\prime} \mathrm{N}$ and $38^{\circ} 57^{\prime}$ to $39^{\circ} 18^{\prime} \mathrm{E}$. Ganta-afeshum is one of the most densely populated (340 people/ $\mathrm{km}^{2}$ ) (BoARD, 2010) and severely degraded . Communal hillside exclosure is one of the land rehabilitation practices that have been practiced in the district.

The districts characterized by rugged topography with altitude ranging from 1400 to $3200 \mathrm{~m}$ with three agro climatic zones: low lands, mid land and high land (BoARD, 2010). The rainfall distribution of the study areas is unimodal. The annual rain fall ranges from 450 to $650 \mathrm{~mm}$, with a mean annual rain fall of $550 \mathrm{~mm}$. The annual temperature ranges from 25 to $34^{\circ} \mathrm{C}$ with a mean annual temperature of $29.5^{\circ} \mathrm{C}$. The dominant soil types by texture in the district vary in ranges of clay, loam, sandy loam and silty loam (BoARD, 2010). The major land cover and land use types are woodland, evergreen scrub, open woodland, bush-land, grassland, cropland, bare soil and rock outcrop (Feoli et al., 2002). Sedentary mixed farming is the main livelihood system of rural society in Ganta-afeshum.

\section{METHODOLOGY}

\subsection{Research Design}

The study site was divided into three blocks as upper, middle, and lower based on slope gradient. Within each block, farmlands with $R$. prinoide intercropping and free of trees at nearby that have similar management (rain-fed, fertilization, cropping) and situation (location, topographic setting, soil type) were identified. From these, farmlands with matured $R$. prinoide trees and 
wheat (selected seed) as companion crop for the last five growing years were considered for study and to install measurement plots in order to address its maximum possible effects. Since, $R$. prinoide intercropping is practiced at different density by different farmer, density of $R$. prinoide trees was the treatment unit. The density of $R$. prinoide intercropping varied due to different planting spacing and vigorousness of individual plants. After preliminary tree inventory on density and canopy cover was done, four treatments were identified. The treatments were dense ( $2 \mathrm{~m}$ spacing and/or $>65 \%$ canopy cover), medium (2-4m spacing and/or 40-65\% canopy cover), sparse (>4m spacing and/or 20-40\% canopy cover) and open (without trees). In each block a total of 12 farm plots (10x10meter) with three scale of density of $R$. prinoide trees and free of trees (control) at nearby were randomly demarcated in wheat field as measurement plots. Wheat has been cultivated uniformly in all farm plots with and without trees for the last five and more years. The design that was employed had a $4 * 2$ factorial arrangement of treatments in randomized complete block design (RCBD) replicated three times, totaling $4 * 2 * 3=24$ experimental units or samples in each block.

Composite soil sample was taken at two different soil depths from the top $0-15 \mathrm{~cm}$ and $15-30 \mathrm{~cm}$ in the late February to early March 2015. Composite soil sample was taken from five sampling points of farmland plot with $R$. prinoide intercropping with three scales of density and open farmland without $R$. prinoide intercropping (control). Thus, 24 composite soil samples were taken from each block. Hence, the total soil sample was 72, 54 samples from farmland with $R$. prinoide intercropping and 18from open farmland without trees (control) which means 36 soil samples from each layer of soil depth.

Undisturbed soil sample was taken using core sampler with $100 \mathrm{cc}$ from all treatments plots at one randomly selected sampling point from top $(0-15 \mathrm{~cm})$ and lower $(15-30 \mathrm{~cm})$ soil depth for the examination of soil moisture and bulk density. The total number of the undisturbed soil sample was same with the disturbed soil sample (72).

\subsection{Soil Analysis and Laboratory Methods}

The collected soil samples were first air dried, then ground and sieved to separate the soil fraction $<2 \mathrm{~mm}$. Then the soil samples were analyzed for organic carbon content by wet oxidation method of Walkley and Black (Schnitzer 1982); total nitrogen by the Kjeldahl method (Bremner and Mulvaney, 1982). Available P determined by Olsen method (Olsen et al., 1954) while available K by neutral ammonium acetate extraction (Merwin and Peach, 1951). Soil pH and EC 
was determined in a 1:2.5 soil to water suspension (Jackson, 1973). Soil moisture content by oven drying at $105^{\circ} \mathrm{C}$ and bulk density (BD) by weighing oven dried $\left(105^{\circ} \mathrm{C}\right)$ soil samples with known volume, $\mathrm{g} / \mathrm{cm} 3$ or t/m3 $(1 \mathrm{~g} / \mathrm{cm} 3=1000 \mathrm{~kg} / \mathrm{m} 3=1 \mathrm{t} / \mathrm{m} 3)$ (Brady and Weil, 2002).

\subsection{Statistical Analysis}

Soil data was subjected to two way analysis of variance (ANOVA) using the General Linear Model (GLM) procedures of SPSS16. Comparison of treatment means performed using Tukey's Significant Difference test at $\mathrm{P}<0.05$ probability level.

\section{RESULTS AND DISCUSSION}

\subsection{Soil Bulk Density (BD)}

The density of the trees significantly brought difference in BD (Table 1). BD was significantly lower on fields with dense $R$. prinoide intercropping than when density of $R$. prinoide is medium, sparse, and open. The interaction between density of trees and soil depth on bulk density was not significant. The higher $\mathrm{BD}$ in sparse $R$. prinoide tress than open might be resulted from the human trampling effect at the time of leaf harvesting while climbed in the dense. BD under and outside Millettia trees revealed that both the $\mathrm{BD}$ of the surface soils and the subsurface soils under the trees were lower than the BD of the surface soils and the subsurface soils in the open areas (Tadesse et al., 2000). Lower BD under the canopy of A. nilotica in a traditional agroforestry system in central India (Pandey et al., 2000) reported, while lower BD under the canopies of $P$. africanum and $C$. apiculatum as compared to open rangeland from Botswana (Aweto and Dikinya, 2003). Moreover, there was lower BD levels under Cordia africana and Croton macrostachyus canopies as compared to open farm (Jiregna et al., 2005) while there was higher bulk density outside the canopy of $F$. thonningii as compared to the canopy zone (Enideg, 2008).

Lower soil BD under the tree species' canopies is presumably due to the effect of litter addition to the soil. This has resulted from organic matter build up in the soil under the canopies relative to levels in soil outside the canopies. Also, the higher concentration of tree roots near the base of the trees may have had the effect of loosening the soil, thereby reducing soil BD. Furthermore, the soil outside the tree canopies dries out more, being exposed to direct solar radiation. This not only accelerates thermally induced soil organic matter decomposition, but results in the shrinking of organic matter and clay colloids, thereby making the soil more compact (Schroth et al., 2003). 


\subsection{Soil Moisture Content (MC)}

Soil moisture content was not significantly affected by varied density of the trees while significantly $(\mathrm{P}<0.05)$ affected by soil depth (Table 1$)$ and the interaction effects of soil depth and density of trees. MC of the surface soils and the subsurface soils under the Millettia trees were higher than the MC of the surface soils and the subsurface soils in the open areas (Tadesse et al., 2000) which corroborate with the findings of the present study. The relatively higher soil MC under dense $R$. prinoide intercropping as compared to soil MC in open farm and lower surface soil as compared to subsurface soils might be due to variation in soil organic matter (SOM) and exposition to evaporation. The relatively better SOM in farms with tree might make the soil to retain water by increasing its surface area and improving the soil structure (Teixeira et al., 2003). It might be also due to the shading effect of the trees. The soil outside the tree canopies might dry out more, being exposed to direct solar radiation whereas the shade provided by the trees would have enhanced the MC under their canopy.

Table 1. Soil physical fertility in farm as influenced by varied density of Rhamnus prinoide (gesho) intercropping and soil depth.

\begin{tabular}{|lllllll|}
\hline $\begin{array}{l}\text { Soil } \\
\text { Physical } \\
\text { Fertility }\end{array}$ & $\begin{array}{l}\text { Soil } \\
\text { depth } \\
(\text { cm })\end{array}$ & Dense & Medium & Sparse & Open & Average \\
\hline $\mathrm{BD}\left(\mathrm{g} / \mathrm{cm}^{3}\right)$ & $0-15$ & $1.195 \pm 0.131$ & $1.253 \pm 0.082$ & $1.322 \pm 0.054$ & $1.263 \pm 0.060$ & $1.258 \pm 0.095$ \\
\cline { 2 - 7 } & $15-30$ & $1.180 \pm 0.083$ & $1.243 \pm 0.125$ & $1.237 \pm 0.076$ & $1.237 \pm 0.073$ & $1.224 \pm 0.091$ \\
\cline { 2 - 7 } & Average & $1.188 \pm 0.106^{\mathrm{A}}$ & $1.248 \pm 0.102^{\mathrm{B}}$ & $1.279 \pm 0.077^{\mathrm{B}}$ & $1.250 \pm 0.066^{\mathrm{B}}$ & \\
\hline \% MC & $0-15$ & $9.798 \pm 1.583^{\mathrm{a}}$ & $12.030 \pm 2.485$ & $9.728 \pm 1.678^{\mathrm{a}}$ & $9.693 \pm 4.279^{\mathrm{a}}$ & $10.313 \pm 2.797^{\mathrm{a}}$ \\
\cline { 2 - 7 } & $15-30$ & $15.130 \pm 1.786^{\mathrm{b}}$ & $12.520 \pm 3.829$ & $13.522 \pm 1.612^{\mathrm{b}}$ & $14.392 \pm 2.930^{\mathrm{b}}$ & $13.891 \pm 2.759^{\mathrm{b}}$ \\
& Average & $12.464 \pm 3.195$ & $12.275 \pm 3.141$ & $11.625 \pm 2.521$ & $12.043 \pm 4.301$ & \\
\hline
\end{tabular}

Note: $\mathrm{BD}=$ Bulk density; $\mathrm{MC}=$ moisture content. Means along the same column (soil depth) and rows (density) with different superscripts are significantly different $(\mathrm{P}<0.05)$; Values are Mean \pm SEM (standard errors of the mean).

Above all, the relatively better soil moisture within farms with $R$. prinoide intercropping compared to farms free of any tree planting disproved the claims that tree planting within farmland in dry land exacerbates shortage of soil moisture and consequently affect productivity of farms. This indicated that it is possible to improve water recharge (Ilstedt et al., 2016) and best utilize scarce moisture in the dry lands through appropriate inter-planting of suitable species. 


\subsection{Soil Nitrogen $(\mathbf{N})$}

Soil $\mathrm{N}$ concentration showed significant variation $(\mathrm{P}<0.05)$ among the different density of $R$. prinoide intercropping and between soil depth (Table 2). Soil N concentration showed decreasing trend with decreasing densities of trees and with increasing soil depth.

The higher total soil $\mathrm{N}$ accumulation in farm with dense trees as compared to soils in open farm of the present study might be attributed to high accumulation of organic matter under tree canopies. Likewise, the shading effect of trees might contribute for better $\mathrm{N}$ concentration in farms with more trees, since it reduce loss of volatile N. An increase in average total nitrogen under $F$. thonningii canopy by $85 \%$ in the surface soil and by $63 \%$ in the subsurface soil depths as compared to soils in the open pasture (Enideg, 2008) is in line with the result of the present study. The total soil $\mathrm{N}$ of surface and subsurface soils was higher under tree canopies by 22 to $26 \%$ for C. africana and 12 to $17 \%$ C. macrostachyus than the corresponding soils away from the tree canopies (Jiregna et al., 2005). There was a significantly higher total soil $\mathrm{N}$ of both surface and subsurface soil under the canopy of Millettia as compared to open area outside the canopy zone of Millettia (Tadesse et al., 2000).

\subsection{Soil Organic Carbon (OC)}

Soil OC was not significantly affected by both the different density of trees and soil depth and their interactions $(\mathrm{P}>0.05)$ (Table 2). The soil OC of the present study can be categorized under high soil OC range value according to Bhandari and Tripathi, (1979). The overall high value of soil OC in farms with different tree cover might be mainly due to the application of manure and compost by farmers. In contrary to the findings of this study, Abebe (1998, unpublished data) found soil organic carbon concentration of top soil under canopy of $C$. Africana in both the range land and crop land ecosystems that were respectively $35 \%$ and $43 \%$ higher than their immediate subsurface soil. Similarly, Tadesse et al. (2000) observed significantly higher soil OC in the surface and subsurface soil beneath canopy as compared to the open field outside canopy of Millettia. Enideg (2008) reported soil OC of surface and subsurface soils under canopy zone of F. thonningii higher by 46.69 and $23.01 \%$, respectively as compared to the surface and subsurface soil beyond the canopy.

\subsection{Soil Carbon to Nitrogen Ratio (C/N)}

The soil $\mathrm{C} / \mathrm{N}$ ratio decreased with decreasing density of trees (Table 2) compared to Enideg (2008, unpublished data) who reported increased C/N ratios with increasing distance from $F$. 
thonninigii and with increasing soil depth. Tadesse et al. (2000) also reported lower C/N ratio under Millettia tree than in the open areas for both the surface and the subsurface soils. This may be due to the varied effects of different tree species on soil carbon and nitrogen. The leguminous species could have lower $\mathrm{C} / \mathrm{N}$ ratio under their canopy compared to non-leguminous species because of their nitrogen enhancing role through their symbiotic relationship with rhizobium. Likewise, the deciduous plants could have higher litter fall compared to evergreen plants.

Table 2. Soil chemical fertility in farm as influenced by the varied density of Rhamnus prinoide (gesho) intercropping and soil depth.

\begin{tabular}{|c|c|c|c|c|c|c|}
\hline \multirow{2}{*}{\begin{tabular}{|l|} 
Soil \\
Chemical \\
Fertility
\end{tabular}} & \multirow{2}{*}{$\begin{array}{l}\text { Soil } \\
\text { Depth } \\
\text { (cm) }\end{array}$} & \multicolumn{5}{|c|}{ Density of Rhamnus prinoide intercropped in wheat farm } \\
\hline & & Dense & Medium & Sparse & Open & Average \\
\hline \multirow{3}{*}{$\% \mathbf{N}$} & $0-15$ & $0.155 \pm 0.032^{\mathrm{a}}$ & $0.139 \pm 0.032$ & $0.130 \pm 0.040^{\mathrm{a}}$ & $0.139 \pm 0.029^{\mathrm{a}}$ & $0.141 \pm 0.033^{\mathrm{a}}$ \\
\hline & $15-30$ & $0.190 \pm 0.131^{\mathrm{b}}$ & $0.127 \pm 0.037$ & $0.107 \pm 0.029^{b}$ & $0.104 \pm 0.032^{\mathrm{b}}$ & $0.119 \pm 0.042^{\mathrm{b}}$ \\
\hline & Average & $0.172 \pm 0.094^{\mathrm{A}}$ & $0.133 \pm 0.034^{\mathrm{B}}$ & $0.118 \pm 0.036^{\mathrm{B}}$ & $0.121 \pm 0.035^{\mathrm{B}}$ & \\
\hline \multirow{3}{*}{ Av. P } & $0-15$ & $3.901 \pm 2.373$ & $4.627 \pm 3.355^{\mathrm{a}}$ & $3.222 \pm 2.741^{\mathrm{a}}$ & $4.072 \pm 2.228^{\mathrm{a}}$ & $3.956 \pm 2.640^{\mathrm{a}}$ \\
\hline & $15-30$ & $3.553 \pm 2.968$ & $1.954 \pm 1.007^{\mathrm{b}}$ & $2.224 \pm 2.410^{\mathrm{b}}$ & $2.153 \pm 1.337^{\mathrm{b}}$ & $2.471 \pm 2.096^{\mathrm{b}}$ \\
\hline & Average & $3.727 \pm 2.613$ & $3.291 \pm 2.769$ & $2.723 \pm 2.556$ & $3.113 \pm 2.038$ & \\
\hline \multirow{3}{*}{$\% \mathrm{OC}$} & $0-15$ & $1.713 \pm 0.853$ & $2.220 \pm 0.554$ & $1.427 \pm 1.009$ & $1.648 \pm 0.727$ & $1.752 \pm 0.823$ \\
\hline & $15-30$ & $1.544 \pm 0.734$ & $1.774 \pm 0.674$ & $1.331 \pm 0.851$ & $1.266 \pm 0.733$ & $1.479 \pm 0.746$ \\
\hline & Average & $1.629 \pm 0.777$ & $1.997 \pm 0.641$ & $1.379 \pm 0.907$ & $1.457 \pm 0.735$ & \\
\hline \multirow{3}{*}{$\mathbf{C} / \mathbf{N}$} & $0-15$ & $10.779 \pm 4.352$ & $16.561 \pm 5.128$ & $10.772 \pm 8.000$ & $11.662 \pm 4.134$ & $12.443 \pm 5.901$ \\
\hline & $15-30$ & $11.486 \pm 3.867$ & $14.114 \pm 4.702$ & $12.355 \pm 8.266$ & $11.811 \pm 5.656$ & $12.442 \pm 5.698$ \\
\hline & Average & $11.133 \pm 4.010$ & $15.337 \pm 4.936$ & $11.564 \pm 7.933$ & $11.736 \pm 4.807$ & \\
\hline \multirow[t]{3}{*}{ Ex. K } & $0-15$ & $0.503 \pm 0.153^{\mathrm{a}}$ & $0.542 \pm 0.152^{\mathrm{a}}$ & $0.472 \pm 0.214^{\mathrm{a}}$ & $0.532 \pm 0.163^{\mathrm{a}}$ & $0.513 \pm 0.167^{a}$ \\
\hline & $15-30$ & $0.332 \pm 0.105^{b}$ & $0.334 \pm 0.109^{b}$ & $0.264 \pm 0.084^{b}$ & $0.357 \pm 0.110^{b}$ & $0.322 \pm 0.104^{\mathrm{b}}$ \\
\hline & Average & $0.418 \pm 0.155$ & $0.438 \pm 0.167$ & $0.368 \pm 0.190$ & $0.444 \pm 0.162$ & \\
\hline \multirow[t]{3}{*}{ Ex. Mg } & $0-15$ & $0.797 \pm 0.687$ & $1.032 \pm 0.982^{\mathrm{a}}$ & $0.612 \pm 0.796^{\mathrm{a}}$ & $0.819 \pm 0.682^{\mathrm{a}}$ & $0.815 \pm 0.776^{a}$ \\
\hline & $15-30$ & $0.723 \pm 0.857$ & $0.238 \pm 0.248^{b}$ & $0.443 \pm 0.631^{b}$ & $0.296 \pm 0.357^{b}$ & $0.425 \pm 0.582^{b}$ \\
\hline & Average & $0.760 \pm 0.754$ & $0.635 \pm 0.806$ & $0.528 \pm 0.702$ & $0.557 \pm 0.593$ & \\
\hline \multirow[t]{3}{*}{ CEC } & $0-15$ & $43.373 \pm 14.119$ & $53.164 \pm 5.894$ & $38.871 \pm 17.136$ & $48.149 \pm 9.855$ & $45.889 \pm 13.116$ \\
\hline & $15-30$ & $44.499 \pm 12.821$ & $49.284 \pm 9.794$ & $40.998 \pm 15.303$ & $42.740 \pm 11.999$ & $44.380 \pm 12.480$ \\
\hline & Average & $43.936 \pm 13.096^{\mathrm{A}}$ & $51.224 \pm 8.091^{\mathrm{B}}$ & $39.934 \pm 15.798^{\mathrm{C}}$ & $45.444 \pm 11.009^{\mathrm{D}}$ & \\
\hline \multirow[t]{3}{*}{ pH } & $0-15$ & $7.367 \pm 0.166$ & $7.300 \pm 0.469$ & $7.467 \pm 0.187$ & $7.489 \pm 0.306$ & $7.406 \pm 0.303$ \\
\hline & $15-30$ & $7.300 \pm 0.350$ & $7.311 \pm 0.420$ & $7.356 \pm 0.288$ & $7.422 \pm 0.327$ & $7.347 \pm 0.338$ \\
\hline & Average & $7.333 \pm 0.268$ & $7.306 \pm 0.432$ & $7.411 \pm 0.242$ & $7.456 \pm 0.309$ & \\
\hline \multirow[t]{3}{*}{ EC } & $0-15$ & $0.112 \pm 0.063$ & $0.097 \pm 0.037$ & $0.099 \pm 0.047$ & $0.171 \pm 0.075$ & $0.120 \pm 0.063$ \\
\hline & $15-30$ & $0.110 \pm 0.060$ & $0.129 \pm 0.074$ & $0.132 \pm 0.097$ & $0.121 \pm 0.092$ & $0.123 \pm 0.079$ \\
\hline & Average & $0.111 \pm 0.060$ & $0.113 \pm 0.059$ & $0.116 \pm 0.076$ & $0.146 \pm 0.085$ & \\
\hline
\end{tabular}

Note: Means along the same column (soil depth) and rows (density) with different superscripts are significantly different $(\mathrm{P}<0.05)$; Values are Mean \pm SEM (standard errors of the mean). 


\subsection{Soil Phosphorus (P)}

Soil $\mathrm{P}$ concentration was not significantly affected by the density of $R$. prinoide intercropping and interaction effect of density and soil depth $(\mathrm{P}>0.05)$ while it is significantly affected by the soil depth $(\mathrm{P}<0.05)$ (Table 2). Soil $\mathrm{P}$ concentration decreased with increasing soil depth. The soil $\mathrm{P}$ concentration of surface soil under dense and open farm was 11.4 and $81.8 \%$ higher than their immediate subsurface soils. The similar soil $\mathrm{P}$ accumulation within farms with different trees cover as compared to open farm of the present study could be due to minimal positive and negative effect of trees density. Results suggest that there is no significant difference in P content between the soils under canopy and open pasture while the average $\mathrm{P}$ content under canopy was 12 and 5\% higher than the open pasture in the surface and subsurface soil depths respectively for the same species. Enideg (2008) also reported the same in a similar study. Tadesse et al. (2000) found available soil $\mathrm{P}$ concentration in the surface soils are significantly higher under the trees than in the open field while in the present case the surface soil $\mathrm{P}$ values are higher than the subsurface, in line with the present investigation.

\subsection{Soil pH}

The lower soil $\mathrm{pH}$ values in farm with dense $R$. prinoide as compared to open might be due to several mechanisms that release $\mathrm{H}^{+}$ions, such as soil base cation uptake (or depletion) by the tree, decomposition of organic matter to organic acids and $\mathrm{CO}_{2}$, root respiration and nitrification. Rhodes (1997) suggested that increased accumulation of aboveground biomass and associated cation uptake by the tree component of agroforestry systems as possibly one of the causes for decreased $\mathrm{pH}$ in soils. According to FAI (1977), soils having $\mathrm{pH}$ value in the range 6.50 to 8.70 are considered normal, that do not require treatment, and are optimum for most crops. Whereas, Tegenu et al. (2008, unpublished data) indicated that the $\mathrm{pH}$ range for most productive agricultural soils varies between 5.5 and 7.5. The mean soil $\mathrm{pH}$ of the soil under dense $R$. prinoide ranged from 7.3 to 7.45 while 7.40 to 7.5 in the open farm. As the soil $\mathrm{pH}$ under dense and in open farm of $R$. prinoide are within the normal recommended range, the soils can support most agricultural crops. Jiregna et al. (2005) and Tadesse et al. (2000) have reported that the presence of C. africana, C. macrostachyus and Millettia trees on farms have no significant influence on $\mathrm{pH}$ that coincide the present study findings. Whereas, Pandey et al. (2000) and Hailemariam et al. (2010) found soil $\mathrm{pH}$ value that differed significantly among density and soil depths under Balanitesa egyptiaca. Rhodes (1997) noticed a lower $\mathrm{pH}$ that ranges from 4.90 to 
6.10 and 5.10 to 6.80 under mid canopy and canopy edge respectively to 5.50 to 6.90 beyond canopy under Pseudotsuga menziesii, Pinus ponderosa, Libocedrus decurrens.

\subsection{Potassium (K)}

Mean soil $\mathrm{K}$ concentration showed a highly significant variation $(\mathrm{P}<0.05)$ with soil depth. The soil surface K concentration under dense trees farm and in open farm were 51.5 and $49 \%$ higher than the respective subsurface soil. The subsurface soil $\mathrm{K}$ concentration under dense trees was $25.76 \%$ higher than the subsurface soil in open farm. The similar soil $\mathrm{K}$ accumulation in farms with different trees density and open farm of the present study could be due to minimal effect of the $R$. prinoide intercropping in either enhancing or exploiting it. The significant difference in $\mathrm{K}$ concentration between soil depths is mainly observed from the open farms that mean the effect of the tree presence across soil depth is minimal. However, the findings from different study on the effect of different tree species on soil K concentration did vary from this study findings. Tadesse et al. (2000) reported significantly higher surface soil K concentration under the Millettia trees than in the open fields; and the surface soil $\mathrm{K}$ concentration higher than the subsurface ones. Besides, Abebe (2006) reported that soil K that was significantly $(\mathrm{P}<0.01)$ affected by all forms of the main effects (tree species, density of trees, soil depth and location) and all forms of their interaction effects from Harrargie of Ethiopia for Acacia albida, $C$. Africana and C. macrostachyus. Enideg (2008) reported similar results under canopy of $F$. thonningii from Gondar, Ethiopia.

\subsection{Magnesium (Mg)}

Soil Mg concentration showed significant variation between soil depth $(\mathrm{P}<0.05)$. Relatively the soil $\mathrm{Mg}$ concentration in topsoil and lower soil under dense trees farm is with slight difference while it is wider in the medium density and open farm. Magnesium $\left(\mathrm{Mg}^{2+}\right)$ is one of the five most abundant cations in soils system (Hazelton and Murphy, 2007). According to Hazelton and Murphy (2007) on levels of exchangeable cations ( $\mathrm{cmol}(+) / \mathrm{kg})$, soil with $\mathrm{Mg}$ concentration within 1-3 are moderate level. Thus the overall mean value 1.1 soil $\mathrm{Mg}$ concentration of farms with different $R$. prinoide trees density is within the moderate levelbut with some values within the lower level from lower soil depth. Afewerk and Chandravanshi, (2012) reported higher amount $\mathrm{Mg}$ concentration in the leaf and stem of $R$. prinoide which might be the reason for overall lower soil Mg concentration. Hence, the lower Mg concentration in the lower soil depth 
might be due to up take by the tree root system while the higher $\mathrm{Mg}$ concentration in the surface soil presumably due to litter fall and relatively lower uptake by the trees.

\section{CONCLUSION}

$R$. prinoide (gesho) intercropping is a dominant farming system in the study site with significant role in the livelihood of communities. The soil nutrient analysis from farms with different $R$. prinoide densities showed no significant difference for most nutrients. As a result the enhancing and exploitative effect of $R$. prinoide on some nutrients at the measured soil depth $(0-30 \mathrm{~cm})$ is minimal. This indicates that incorporating trees with different resource requirement and utilization zone in farm enhance productivity and efficiency of resource utilization. Above all, the relatively better soil moisture within farms with $R$. prinoide intercropping compared to farms free of any tree planting disproved the claims that tree planting within farmland in dry land exacerbates shortage of soil moisture and consequently affect productivity of farms. This indicated that it is possible to best utilize scarce moisture through appropriate inter-planting of suitable species in the dry lands. Hence, these could be the reasons that $R$. prinoide intercropping is being practiced by most farmers and maintained through generation in the study areas and nearby.

\section{ACKNOWLEDGMENTS}

We would like to thank Mekelle University for the research fund and the farmers for allow us to take soil samples from their farm.

\section{REFERENCE}

Abebe, N. 2006. Soil Fertility Status under Indigenous Tree Canopies on Farmland in Selected Areas of Eastern and Western Haragehe Zone. M.Sc. Thesis, Haramaya University, Haramaya, Ethiopia, pp25-39.

Abebe, Y. 1998. Evaluation of the Contribution of Scattered Cordia africana Trees to Soil Properties in Cropland and Rangeland Ecosystems in Western Oromia, Ethiopia. M.Sc. Thesis, ISSN 1402 -201X (36) SLU, Sweden, pp27-39. 
Afewerk, G \& Chandravanshi, B.S. 2012. Levels of essential and non-essential metals in Rhamnusprinoides (gesho) cultivated in Ethiopia. Bulletin of the Chemical Society of Ethiopia, 26(3):329-342.

Andemariam, S.W. 2010. Legislative Regulation of traditional medicinal knowledge in Eritrea Vis-À-Vis Eritrea's commitments under the convention on biological diversity. LEAD, 6: 133-162.

Aweto, A.O \& Dikinya, O. 2003. The Beneficial Effects of Two Tree Species on Soil Properties in a Semi-Arid Savanna Rangeland in Botswana. Land Contam. Reclam. 11(3):339-334.

Berhanu, A. \& Teshome, K. 1995. Bitter Principle of Rhamnus prinoides and Other Constituents of the Leaves. Bulletin of the Chemical Society of Ethiopia, 9(2):107-114.

Bhandari, A. K \& Tripathi, B. R. 1979. Soil testing in fertilizer recommendations. Department of Soil Science and Chemistry, Himachal Pradesh, Shimla, Technical Bulletin No. 10.

Birhanu, Z. 2013. Traditional use of medicinal plants by the ethnic groups of Gondar Zuria District, Northwestern Ethiopia. J Nat Remedies, 13:47-53.

Brady, N.C \& Weil R.R. 2002. Nature and Properties of Soils. $13^{\text {th }}$ edition, Prentice- Hall Inc., ISBN 9780130167637-13, 2pp.

Bremner, J.M \& Mulvaney, C.S. 1982. Nitrogen-Total. In: Page, A.L., Miller, R.H., Keeney, D.R (eds). Methods of Soil Analysis, 2:595-622.

Bureau of Agriculture and Rural Development (BoARD). 2010. Ganta-Afeshum district annual report. Adigrat, EasternTigray region, Ethiopia.

Cooper, P.J.M., Leakey, R.R.B., Rao, M.R \& Reynolds, L. 1996. Agroforestry and the mitigation of land degradation in the humid and sub-humid tropics of Africa. Experimental Agriculture, 32: 235-290.

d'Avigdor, E., Wohlmuth, H., Asfaw, Z \& Awas, T. 2014. The current status of knowledge of herbal medicine and medicinal plants in Fiche, Ethiopia. J Ethnobiol. Ethnomed., 10: 38.

Enideg, D. 2008. Importance of Ficus thonningii Blume in Soil Fertility improvement and Animal Nutrition in Gondar Zuria, Ethiopia. M.Sc.Thesis, University of Natural Resources and Applied Life Science, Vienna, pp23-45.

FAI 1977. Hand Book of Fertilizer Usage. Fertilizer Association of India, New Delhi, India, ISBN 110 067, 60p. 
Hailemariam, K., Kindeya, G \& Yamoah, C. 2010. Balanitesaegyptiaca, a Potential Tree for Parkland Agroforestry Systems with Sorghum in Northern Ethiopia. J. Soil Sci. Environ. Manag., 1(6):107-114.

Hazelton, P \& Murphy, B. 2007. Interpreting Soil test results. CSIRO Publishing, 150 Oxford Street, Collingwood VIC 3066, Australia, ISBN 978064309225 9, 65p.

Ilstedt, U., Bargués, T.A., Bazié H.R., Bayala, J., Verbeeten, E., Nyberg, G.,Sanou, J., Benegas, L.,Murdiyarso, D.,Laudon, H., Sheil, D \& Malmer, A. 2016. Intermediate tree cover can maximize groundwater recharge in the seasonally dry tropics. Scientific Report no.6, 12p.

Jackson, M.L. 1973. Soil Chemical Analysis. Prentice Hall Pvt. Ltd., New Delhi, India, ISBN30843 6, 498p.

Jiregna, G., Rozanov, A \& Legesse, N. 2005. Trees on Farms and Their Contribution to Soil Fertility Parameters in Badessa, Eastern Ethiopia. Biol. Fertil. Soils, 42:66-71.

Kiniry, J. R., Macdonald, J. D., Kemanian, A. R., Watson, B., Putz, G \& Prepas, E.E. 2008. Plant growth simulation for landscape-scale hydrological modeling. Hydrological Sciences Journal, 53(5):1030-1042

Kokwaro, J.O. 1993. Medicinal plants of East Africa. Kenya Literature Bureau, Nairobi, Kenya, ISBN 996644190 5, 401p.

Merwin, H.D \& Peech, M. 1951. Exchangeability of soil potassium in sand, silt and clay fraction as influenced by the nature of complementary exchangeable cations. Soil Sci. Soc. Am., 15:125-128.

Olsen, S.R., Cole, C.V., Watanabe, F.S \& Dean, L.A. 1954. Estimation of Available Phosphorus in Soil by Extraction with NaHCO3: Washington DC, US Department of Agriculture Circular no. 939, 19p.

Orwa, C., Mutua, A., Kindt, R., Jamnadass, R \& Anthony, S. 2009. Agroforestree Database: a tree reference and selection guide version 4.0. World Agroforestry Centre, Kenya. (http://www.worldagroforestry.org/publication/agroforestree-database-tree-species-reference and-selection-guide-version-40).

Pandey, C.B., Singh, A.K \& Sharma, D.K. 2000. Soil Properties under Acacia nilotica Trees in a Traditional Agroforestry System in Central India. Agroforest. Syst., 49:53-61.

Rhodes, C.C. 1997. Single-Tree Influences on Soil Properties in Agroforestry: Lessons from Natural Forest and Savannah Ecosystems. Agroforest. Syst., 35:71-94. 
Schnitzer, M. 1982. Total Carbon, Organic Matter and Carbon. In: Page, A.L., Miller, R.H., Keeney, D.R. (eds) Methods of soil analysis, 9:539-577.

Schroth, G \& Sinclair, F.L. 2003. Impacts of Trees on the Fertility of Agricultural Soils. In: Schroth, G. \& Sinclair, F.L. Trees, crops and soil fertility: concepts and research methods. CAB International, 1:1-11.

Schroth, G., Lehmann, J \& Barrios, E. 2003. Soil Nutrient Availability and Acidity. In: Schroth, G. \& Sinclair, F.L. Trees, crops and soil fertility: concepts and research methods. CAB International, 5:93-127.

Smaling, E.M.A., Nandwa, S.M \& Janssen, B.H. 1997. Soil fertility in Africa is at stake. In: Buresh, R.J., Sanchez, P.A. and Calhoun, F. (eds) Replenishing Soil Fertility in Africa. Soil Science Society of America, Madison, Wisconsin, pp47-61.

Tadesse, H., Legesse, N \& Olsson, M. 2000. Millettiaferruginea from Southern Ethiopia: Impacts on Soil Fertility and Growth of Maize. Agroforest. Syst., 48:9-24.

Teixeira, W.G., Sinclair, F.L., Huwe B \& Schroth, G. 2003. Soil Water. In: Schroth, G. \& Sinclair, F.L. Trees, crops and soil fertility: concepts and research methods. $C A B$ International, 11:209-232.

UNEP, 1992. World Atlas of Desertification. Edward Arnold, London, 69p.

Van Noordwijk, M. 1999. Scale effects in crop-fallow rotations. Agroforestry Systems, 47:239251.

Van Noordwijk, M., Poulsen, J., Ericksen, P., Ong, C.K \& Walsh, M. 1999. Filters, flows and fallacies: methods for quantifying external effects of land use change. In: Workshop on Environmental Services and Land Use Change, Chiang Mai, Thailand. ASB-Indonesia report no. 10, ICRAF, Bogor, 10p.

Vandermeer, J.H. 1992. The ecology of intercropping. Cambridge University Press, New York, ISBN: 052134592 8, pp68-86. 